\title{
Interdisciplinary treatment of spina bifida children
}

\author{
T Redaelli MD ${ }^{1}$ A Cassinis MD,${ }^{1} \mathrm{~F}$ Cosignani MD, ${ }^{1} \mathrm{~B}$ Conti MD,${ }^{1}$ MP Onofri MD,${ }^{2} \mathrm{~A}$ \\ Dall'Acqua $\mathrm{MD}^{2}$
}

${ }^{1}$ Institute of Physical Medicine and Rehabilitation, ${ }^{2}$ Child Neuropsychiatric Service, Niguarda Ca' Granda Hospital, 20162 Milan, Italy.

In the Spina Bifida Centre, Niguarda Ca' Granda Hospital (Milan, Italy), from June 1985 to June 1990, 60 spina bifida children have been treated. The results of the rehabilitation programme (including orthopaedic, urological and psychosocial aspects) at the time of the survey were:

(a) Neuromotor function: $72 \%$ of the patients achieved ambulation, $52 \%$ of these being less than 2 years of age, and $20 \%$ older than 2 years; $18 \%$ were too young for walking. Thus, considering the children's age, about $90 \%$ of the subjects achieved the standing position, and $89 \%$ achieved ambulation.

(b) Bladder function: $83 \%$ of the children had a complete urological evaluation; $40 \%$ of those with a neuropathic bladder had a hyperreflexic type, 54\% areflexic, and $6 \%$ normoreflexic. Thirty-two percent of the patients had signs of 'high pressure' bladder function. Urinary continence was: $36 \% \geqslant 2$ hours, $20 \%<2$ hours, $44 \%$ not detectable (age $<2$ years). Forty percent of the subjects used intermittent catheterisation.

(c) Psychosocial aspect: child adaptation to the disease and to the rehabilitation programme was good in $61 \%$ of the patients; family problems were identified in $70 \%$ of the patients; enrolment in preschool and school programmes was normal (or with specialist teaching) in about $74 \% ; 33.3 \%$ of the subjects had disturbance of affect.

The results clearly showed that the interdisciplinary approach favoured the social integration of these children.

Keywords: spina bifida; neuropathic bladder; rehabilitation; psychosocial problems.

\section{Introduction}

The aim of the physiatrist in the treatment of the spina bifida child is to promote a developmental model close to 'normality', taking into account the neurological level. In the global treatment schedule of such patients, we have found neurosurgical, neurological, orthopaedic, urological, rehabilitation and neuropsychological problems. Thus the therapeutic protocol should be interdisciplinary with the integrated work of several specialists assuring early and suitable intervention, along with positive cooperation from the children' parents. ${ }^{1,2}$ This is the aim of the Spina Bifida Centre of the Niguarda Ca' Granda Hospital in Milan (Italy), which has been working in this field for 7 years and receives children from all over Italy.
We have examined the results of this methodological approach, considering the most important aspects which characterise the rehabilitation programme of the spina bifida child. These are (a) neuromotor function; (b) urinary bladder function; and (c) psychosocial aspects.

\section{Patients and methods}

Neuromotor function

In our Centre, from $6 / 1 / 85$ to $6 / 30 / 90,60$ spina bifida (SB) children have been treated. Their age at the time of the first observation was: 36 patients $\leqslant 2$ months, 8 patients between 2 months and 3 years, 16 patients $\geqslant 3$ years.

The average age of the closure surgery was 2.3 days ( $\min 1$ day, $\max 10$ days) in 
females and 8.9 days (min 1 day, $\max 150$ days) in males. Forty-four subjects had a ventriculo-peritoneal shunt at an average age of 20.5 days ( $\min 1$ day, $\max 180$ days).

All the patients had been examined by the medical team working in the Centre and had followed the rehabilitation programme from the time of the first observation. ${ }^{3,4}$

The subjects' neurological level was determined by assessing the last functioning level, considering the most important muscular groups for ambulation. When patients had different levels of function for each leg, the leg with the least function was used for classification purposes (Fig 1).

\section{Urinary bladder function}

We studied 50 SB children whose age at the first observation was in the range of 3 months-14 years (average age 48.9 months), and at the second observation 9 months-14 years (average age 54.8 months); the time between the first and the second control was 6 months (Fig 2).

At the first observation, each patient underwent the following clinical-diagnostic protocol: ${ }^{5}$ laboratory tests to study renal function; complete urinalysis with culture of the urine; cystourethrography; renal and bladder ultrasonography; renal scintigraphy (DTPA); urodynamic examination.

At the second control the patients only had the laboratory tests and the urodynamic examination, with the exception of the so-called 'risk bladders', defined by the following parameters: dysfunction of the upper urinary tract revealed by diagnostic imaging; 'high pressure' bladder; dyssynergic bladder.

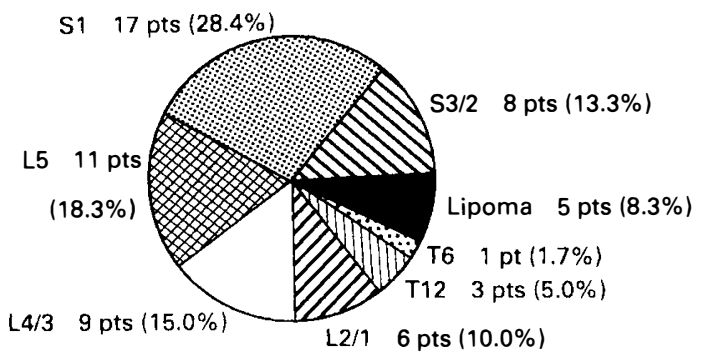

Figure 1 Total number of spina bifida children $(n=60)$ under observation.

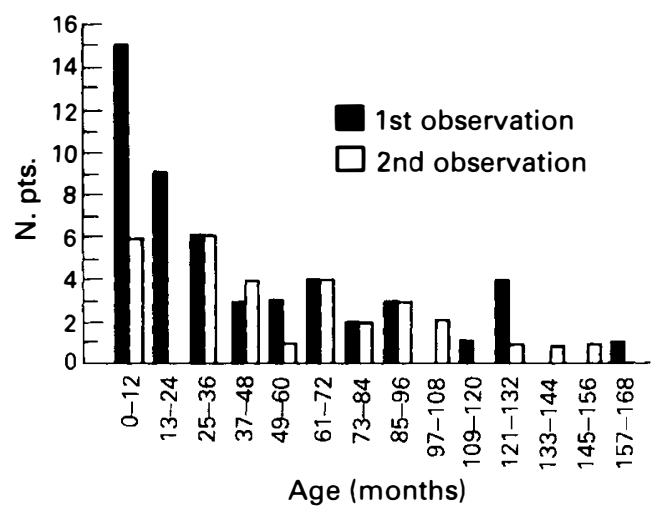

Figure 2 Children under urological evaluation $(\mathrm{n}=50)$ : first and second observation.

One of the most important goals of the urorehabilitation programme is to solve the problem of continence. In this regard we have considered the following parameters: 'functional' continence for more than 2 hours; 'pathological' continence for less than 2 hours. 6,7

\section{Psychosocial aspects}

We assessed mental structure, acceptance of illness, and adaptation to school and family problems in $59 \mathrm{SB}$ children whose age ranged between 16 years and less than 12 months. This study was performed by means of several interviews with each family, and observations of the child's behaviour.

In about a third of the patients we tested personality and cognitive functions, while in the remaining patients we considered the judgements of other medical or educational specialists. We also tried to see if there was a correlation between our findings and the severity of the disease (ie level of damage, hydrocephalus, CNS problems).

\section{Results}

\section{Neuromotor function}

We took into consideration congenital and acquired deformities, classified according to the anatomical location: vertebral column, hip, knee and foot. ${ }^{8,9}$ The results are shown in Figures 3 and 4 . The treatment of such deformities necessitated surgery in 29 patients (Table I). 


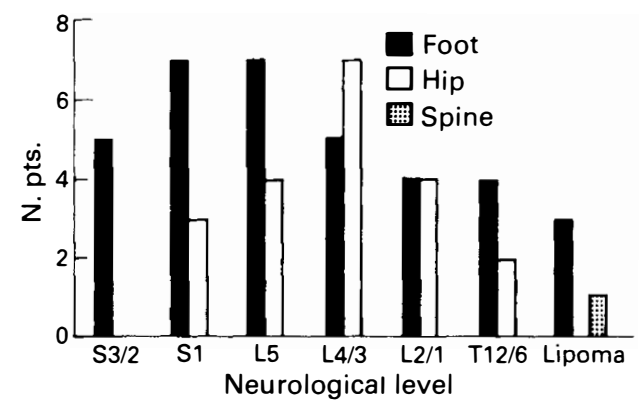

Figure 3 Congenital deformities.

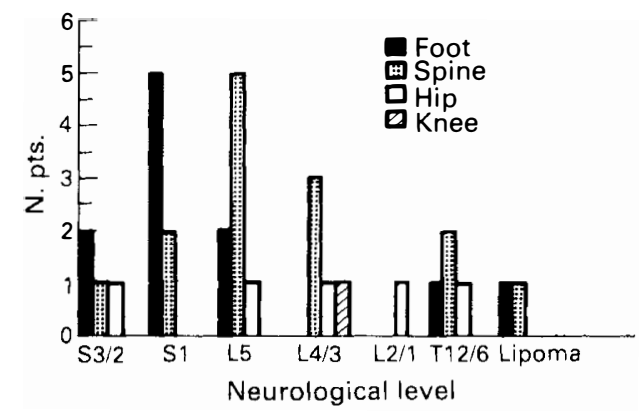

Figure 4 Acquired deformities.

Regarding functional aspects, we evaluated the fundamental goals of the child's neuromotor development, that is, both standing and ambulation, without taking into. account the types of the orthoses that may be being used. The subjects were 0 to 36 months old at the first control; all of them (44 patients) had undergone the rehabilitation programme, according to the instructions in our centre (Fig 5). The rehabilitation team's objective was to have the patient standing up before the age of 15 months, except in the presence of neurological or

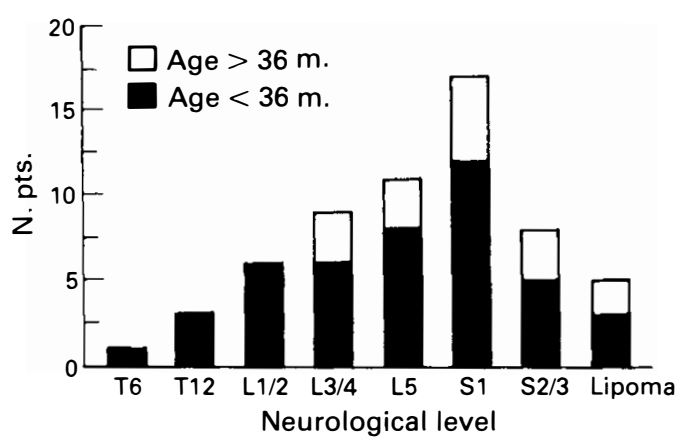

Figure 5 Subjects under neuromotor observation at the first control.

orthopaedic complications. The standing schedule was: $t \leqslant 15$ months, 16 months $\leqslant t \leqslant 24$ months, $t>24$ months. The results of the study are shown in Figure 6. Ambulation was evaluated according to the same time schedule. The study has provided the following data: $20 \%$ of the patients $(n=9)$ walked before 15 months of age, $32 \%(n=14)$ walked between 16 months

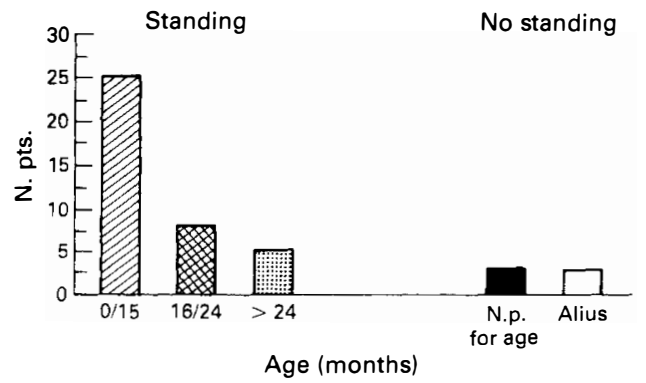

Figure 6 Achievement of the standing position in relation to the patient's age. N.p. $=$ not practical for the very young. Alius $=1$ child suffering from central damage, 1 child with orthopaedic complications, 1 child dead.

Table I Surgical treatment

\begin{tabular}{lll}
\hline Site & Soft tissue & Bone \\
\hline Spine & & 1 Arthrodesis \\
Hip & 5 Tenotomies & 1 Femoral osteotomy \\
& 2 Sharrard & 2 Cotyloid cavity's reconstruction \\
Foot & 6 Tenotomies & 3 Grice \\
& 2 Tendinous transpositions & 1 Dwyer \\
& 4 Capsulotomies & 1 Tarșal osteotomy \\
\hline
\end{tabular}


and 24 months, 20\% $(\mathrm{n}=9)$ after 24 months; $18 \%$ of the patients $(n=8)$ were not included because of age and $10 \%$ $(n=4)$ were excluded from the study (Fig 7).

With regard to ambulation, $84 \%$ of our patients walked indoors, and $37 \%$ walked both indoors and outdoors (Fig 8).

\section{Urinary bladder function}

The urodynamic study revealed the following data: $54 \%$ with areflexic bladders, $40 \%$ with hyperreflexic bladders, $6 \%$ had normoreflexic bladders. At the first study $26 \%$ of bladders showed dysfunction of the upper urinary tract revealed by diagnostic imaging (38.4\% by ultrasonography, $61.5 \%$ by cystourethrography, $84.6 \%$ by renal scintigraphy); $61 \%$ of these showed a pattern of high pressure bladders at the urodynamic

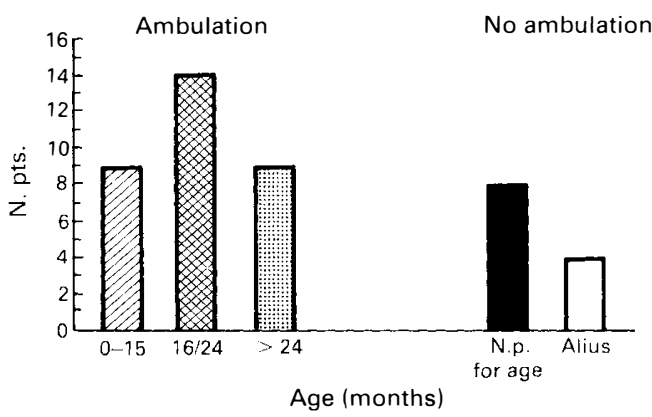

Figure 7 Achievement of ambulation in relation to patient's age. N.p. = not practical for the very young. Alius $=4$ patients excluded from the study.

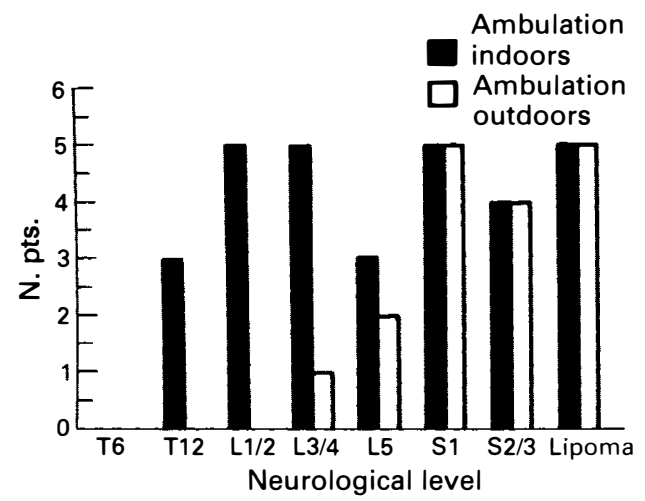

Figure 8 Functionality of ambulation. test. Vesico-sphincteric dyssynergia was detected in $28 \%$ of patients, 6 hyperreflexic bladders, 8 areflexic bladders.

In the first study, the urodynamic investigations showed $32 \%$ with a high-pressure bladder; at the second control $19 \%$ of these had a normal pressure pattern, $56 \%$ partial improvement, and $25 \%$ no change. The results concerning continence are shown in Figure 9.

\section{Psychosocial aspects}

\section{Mental disturbances}

We found mental disturbances, of various types, in 20 of our 59 subjects $(33.9 \%)$. They were more frequent in children with more serious spinal damage and were strictly related to hydrocephalus and other neurological complications (Tables II, III, IV).

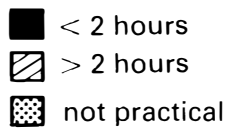

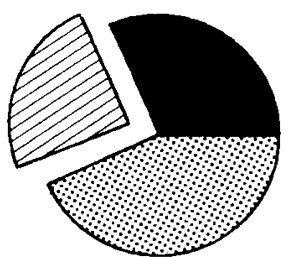

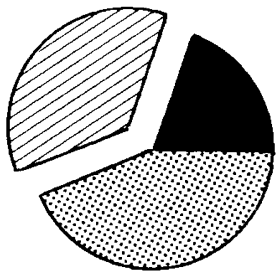

b
Figure 9 Improvement of continence $(>2$ hours) after 6 months of therapy. (a) First control (dry time $>2$ hours in $24 \%$ of the patients); (b) Second control (dry time $>2$ hours in $36 \%$ of the patients).

Table II Mental disturbances in 20 of 59 children

Number of patients

\begin{tabular}{lrr}
\hline Serious mental retardation & 2 & $(3.4 \%)$ \\
Slight-medium mental & & \\
$\quad$ retardation & 11 & $(18.6 \%)$ \\
Psychosis & 4 & $(6.8 \%)$ \\
Neurotic disturbances & 3 & $(5.1 \%)$ \\
Total & $20(33.9 \%)$ \\
\hline
\end{tabular}


Table III Hydrocephalus and other neurological complications in 59 subjects

\begin{tabular}{lc} 
& Number of patients \\
\hline Hydrocephalus & $44(75 \%)$ \\
Strabismus & $26(44 \%)$ \\
Seizures & $6(10 \%)$ \\
Central motor damage & $3(5 \%)$ \\
Central sensory damage & $1(1.9 \%)$ \\
\hline
\end{tabular}

Table IV Hydrocephalus and other neurological complications in 20 mentally disturbed children

\begin{tabular}{lrc} 
& \multicolumn{2}{c}{ Number of patients } \\
\hline Hydrocephalus & 20 & $(100 \%)$ \\
Strabismus & 15 & $(75 \%)$ \\
Seizures & 5 & $(25 \%)$ \\
Central motor damage & 3 & $(15 \%)$ \\
Central sensory damage & 1 & $(5 \%)$ \\
\hline
\end{tabular}

\section{Adaptation to illness}

We considered that 37 patients were sufficiently adapted $(61 \%)$, whilst the other 22 patients $(39 \%)$ were clearly not adapted, and we have noted a poor correlation between the severity of spinal neural damage and adaptation. We found the following negative factors: additional medical problems; prolonged hospitalisation and repeated surgical treatments; too prolonged rehabilitation; fragmentation of specialist medical assistance; lack of social aid, when needed; previous weakness of the family.

\section{Educational problems}

School attendance of our 59 subjects and the assistance of specialist teachers are set out in Table V. Six subjects with serious cognitive

Table V School attendance and educational aid

\begin{tabular}{|c|c|c|}
\hline Age & $\begin{array}{c}\text { School } \\
\text { attendance }\end{array}$ & $\begin{array}{l}\text { Specialist } \\
\text { teachers }\end{array}$ \\
\hline$<3$ years & $(5 \%)$ & $(0 \%)$ \\
\hline $3-5$ years & $11 \quad(75 \%)$ & $6 \quad(55 \%)$ \\
\hline $6-15$ years & $22(100 \%)$ & $11 \quad(50 \%)$ \\
\hline$>15$ years & $1(100 \%)$ & $1(100 \%)$ \\
\hline
\end{tabular}

problems had special individual programmes; the remainder followed the class programme, but many had learning disabilities.

\section{Family problems}

Forty-one of 59 families $(70 \%)$ had problems, which were different in nature and in importance. The problems were considered to be severe in 15 patients and less serious in 26 . We found the following types of problems: child abandoned at birth (2 cases); personal problems between parents and/or siblings (15 cases); separation or divorce (5 cases); psychological suffering of parents and/or siblings (8 cases); financial problems (poverty, or mother giving up her work) (6 cases); social isolation of the whole family ( 5 cases).

\section{Discussion}

\section{Neuromotor function}

The analysis of the results on the deformities has led to the following observations.

The hip and foot are the most frequent congenital deformities; vertebral abnormalities on the other hand are the commonest acquired deformities (Figs 3,4). This is probably due to the etiology (tethered cord), and to the prophylactic role of rehabilitation. ${ }^{10}$

The distribution of congenital deformities of the feet (Fig 10) is fairly homogeneous in all the neurological levels (except for an increase in thoracic lesions); whereas hip deformities are most frequent in those with lumbar neurological lesions, that is $\mathrm{L} 3 / \mathrm{L} 4$, L1/L2 (Fig 11). This is probably due to neuromuscular imbalance between flexoradductor muscles and extensor-abductor

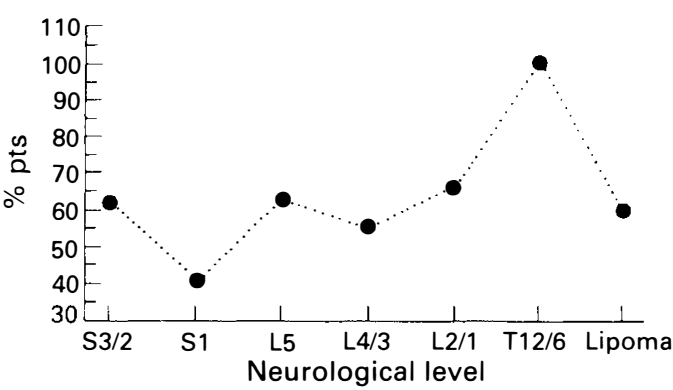

Figure 10 Congenital deformities of the foot. 


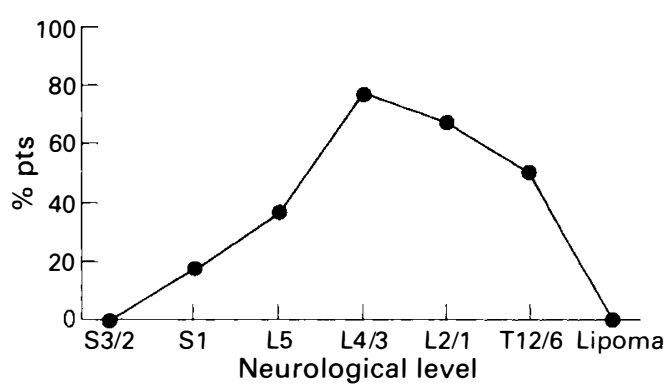

Figure 11 Congenital deformities of the hip.

muscles. We have not found the same pattern with acquired hip deformities, perhaps owing to early rehabilitation.

The data on functional recovery have validated our methodological approach. Nearly all the patients achieved a standing position, more than $50 \%$ of the subjects in respect of a physiological time schedule. Seventy-two percent of the patients achieved ambulation: $52 \%$ when under 2 years of age, $20 \%$ when over 2 years of age; $18 \%$ were too young for walking. Thus, omitting the latter group, about $90 \%$ of the subjects achieved a standing position, and $89 \%$ of the patients could walk.

\section{Urinary bladder function}

With regard to bladder function we conclude that there is no exact correlation between the neurological level of the lesion and the type of vesicosphincteric dysfunction. On the other hand, the basic neurological lesion is developmental, and may be modified in time, due to many factors: the anatomical lesions are often incomplete; growth of the child may modify such lesions; many aggravating factors overlap, such as inadequate treatment, bladder overdistension, and urinary infections.

It is well known that the goals of the rehabilitation programme are: (1) preservation of renal function; and (2) improvement in socialisation: obtaining urinary continence acceptable from the social point of view. As regards topic (1), $75 \%$ of the patients suffering from a 'risk bladder' showed an improvement in bladder pressure, saving renal function; $30 \%$ of these children were managed with intermittent catheterisation, and $12 \%$ took oxybutynin. As regards topic (2), after 6 months of observation, $12 \%$ of the children (from $24 \%$ to $36 \%$ ) improved their time-continence ( 2 hours) and $40 \%$ have been managed with intermittent catheterisation and selfcatheterisation when 5-6 years of age. ${ }^{11,12}$

\section{Psychosocial aspects}

Mental disturbances are clearly related to neurological complications, but we also feel that psychogenic factors are involved. The data supporting this thesis are: first, we rarely found mental disturbances in the first year of life; second, the mental disturbances are not stable and/or they increase during life. Finally, we have found different types of mental abnormality, from psychosis to neurosis, to clear evidence of psychological distress, even in patients with mental retardation. The French School have already demonstrated the connection between the neurological lesion and reactive factors in children with different types of neurological damage. The study of the child and the family adaptation to illness, and of family problems, confirmed the importance of reactive psychological factors in the development of spina bifida children. Sixty-one patients were well adapted, but all showed some signs of fatigue from their medical care, not depending on the degree of the disease. We now have better knowledge of spina bifida, and new techniques are available with surgery and in rehabilitation.

Thus the outlook is better now for these children, but the families have a greater responsibility. A special time in the life of our patients is adolescence, when they try to be independent from their parents, and they discover their sexuality. At this time, the realisation of the differences between a normal and an abnormal body creates an acute psychological distress. All of our children attended a primary and secondary school; 6 had a reduced programme and only $50 \%$ had special teachers.

\section{Conclusions}

The analysis of our results shows that the objectives of spina bifida treatment have 
been fulfilled: to prevent and/or ameliorate complications due to muscular derangement and the neurological level; to promote compensatory functions; and to respect neuromotor goal chronology, impaired by the paralysis and the associated cerebral damage. ${ }^{13}$

The aim of the rehabilitation programme was to give to the spina bifida child all the means to achieve neuromotor abilities appropriate to his own age, and to promote physiological psycho-affective development. ${ }^{14}$ Growing up with spina bifida is a very serious experience for the child and his family. Adequate help consists not only in good specialist medical care, but also in a good global medical, psychological and social approach to the situation. This is a difficult goal for all of the therapists concerned.

\section{References}

1 Alexander MA, Steg NL (1989) Myelomeningocele: comprehensive treatment. Arch Phys Med Rehabil 70: 637-641.

2 Badell A, Binder H, Dykstra D (1989) Pediatric Rehabilitation. 3. Disorders of the spinal cord: spinal cord injury, myelodysplasia. Arch Phys Med Rehabil 70: 170-174.

3 Gross RH, Cox A, Pollay M, Tatyrek R, Barnes A (1983) Early management and decision making for treatment of myelomeningocele. Pediatrics 72: 450-458.

4 Hirsch JF, Pierre-Kahn A (1988) Lumbosacral lipomas with spina bifida. Child's Nerve Syst 4: 354-360.

5 Redaelli T, Combi F, Radaelli E (1984) Rehabilitation of neurogenic bladder: therapeutic value of a methodological study. In: Rossier A, Radaelli E, Redaelli T, editors. Paraplegia and Tetraplegia. Libreria Scientifica giá Ghedini, Milan: 181-196.

6 Bauer SB (1984) Management of neurogenic bladder dysfunction in children. J Urol 132: 544-545.

7 Cass AS, Luxemberg M, Gleich P, Johnson F, Hagen S (1984) Clean intermittent catheterization in management of neurogenic bladder in children. J Urol 132: 526-530.

8 Caroll N (1983) The orthopaedic and orthotic management of the spina bifida child. Clin Neurosurg 30: $413-435$.

9 Sharrard WJW (1983) Management of paralytic subluxation and dislocation of the hip in myelomeningocele. Develop Med Child Neurol 25: 374-376.

10 Nakamura T, Sofue M, Homma T (1988) Spina bifida occulta associated with a low-placed conus medullaris. J Spinal Cord 1: 194-201.

11 Uehling DT, Smith J, Meyer J (1985) Impact of an intermittent catheterization program on children with myelomeningocele. Pediatrics 76: 892-895.

12 Cass AS, Luxemburg M, Johnson CF (1984) Management of neurogenic bladder in 413 children. J Urol 132: $521-525$.

13 Charney EB, Weller SC, Sutton LN (1985) Management of the newborn with myelomeningocele: time for a decision-making process. Pediatrics 75: 58-64.

14 Findley TW, Birkebak RR, McNally MC (1987) Ambulation in the adolescent with myelomeningocele. I: early childhood predictors. Arch Phys Med Rehabil 68: 518-522. 